\title{
LoopAcademic: uma Plataforma Web para o Ensino-Aprendizagem de Programação Introdutória
}

\author{
Dyego Souza, Jarbele Coutinho e Reudismam Sousa \\ Universidade Federal Rural do Semi-Árido \\ Pau dos Ferros, RN, Brazil \\ \{dyego.souza,jarbele.coutinho,reudismam.sousa\}@ufersa.edu.br
}

Nos cursos de ensino superior na área de Computação, os discentes costumam apresentar dificuldades com disciplinas de programação de introdutória [1-7]. Esse problema pode ser decorrente de alguns fatores como a escassez de disciplinas no ensino básico com características voltadas para a programação.

Essas dificuldades podem causar vários transtornos para as instituições de ensino, tais como evasão, desistência, retenção e alocação de novos servidores para atender a demanda crescente de discentes em disciplinas com essas características.

Para possibilitar o uso de intervenções que possam minimizar os problemas apresentados pelos discentes, neste trabalho é proposta uma plataforma Web, LoopACADEMIC, que visa apoiar o ensinoaprendizagem de conteúdos de programação introdutória e proporcionar ao professor ou monitor um acompanhamento mais direcionado à individualidade da aprendizagem do aluno. Esta plataforma foi projetada, através do processo formal proposto por Garret (2010).

O processo de projetos de sistemas definido por Garret (2010) é composto por cinco etapas: estratégia, escopo, estrutura, esqueleto e superfície.

Na etapa de Estratégia foi realizado um Survey com alunos, professores e monitores de uma disciplina de programação introdutória. O questionário eletrônico foi aplicado via Web e divulgado via correio eletrônico e redes sociais. Os resultados obtidos com este Survey resultaram nos requisitos funcionais, nos protótipos de alta fidelidade e na realização dos Testes de Usabilidade do Módulo Aluno da plataforma LoopAcADEMIC.

Na etapa de Escopo foram especificados e modelados os requisitos funcionais do LoopAcademic através de um Diagrama de Caso de Uso. Destacam-se: tarefas de programação, material de apoio (e.g., videoaulas), lista de exercícios, dados de desempenho, dúvidas, fóruns, emblemas, dentre outros.

Na etapa de Estrutura foi adotada o uso da técnica de Card Sorting. Desse modo as funcionalidades foram organizadas em 7 (sete) grupos: (i) login; (ii) listas de exercícios; (iii) material de apoio; (iv) desempenho; (v) dúvidas; (vi) fórum e (vii) emblemas.

$\mathrm{Na}$ etapa de Esqueleto foi realizada a prototipação de baixa fidelidade, com o intuito de explorar aspectos da interface em conjunto com um esboço inicial das funcionalidades.

$\mathrm{Na}$ etapa de Superfície foi desenvolvido os protótipos de alta fidelidade através do software Adobe XD. A Figura 1 apresenta o

Fica permitido ao(s) autor(es) ou a terceiros a reprodução ou distribuição, em parte ou no todo, do material extraído dessa obra, de forma verbatim, adaptada ou remixada, bem como a criação ou produção a partir do conteúdo dessa obra, para fins não comerciais, desde que sejam atribuídos os devidos créditos à criação original, sob os termos da licença CC BY-NC 4.0.

EduComp'21, Abril 26-30, 2021, Jataí, Goiás, Brasil (On-line)

(C) 2021 Copyright mantido pelo(s) autor(es). Direitos de publicação licenciados à Sociedade Brasileira de Computação (SBC). protótipo de alta fidelidade modelado para a funcionalidade Material de Apoio.

Mais informações referentes aos resultados do Survey, aos requisitos, protótipos, personas, análise comparativa com outros ambientes, etc. podem ser vistas no endereço Web https://www.sites. google.com/view/repositorioloopacademic/.

Figura 1: Tela de Material de Apoio - Estruturas de Decisão.

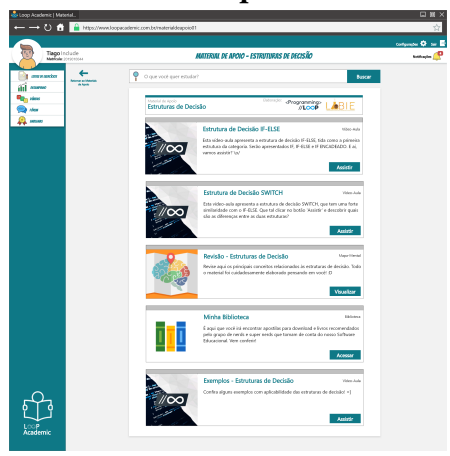

Pretende-se como trabalhos futuros: (i) aplicar a Inspeção de Usabilidade nos protótipos, para validação das funcionalidades; (ii) prototipar os módulos Professor e Monitor; (iii) implementar os módulos Aluno, Professor e Monitor; (iv) realizar uma avaliação pedagógica e funcional dos Módulos desenvolvidos; (v) realizar estudos de casos com a plataforma Web LoopAcAdemic.

\section{REFERÊNCIAS}

[1] Reudismam Rolim, Felipe Torres Leite, Adller de Oliveira Guimara es, and Assunaueny Rodrigues de Oliveira. Pré-algoritmos - ações de apoio à melhoria do ensino de graduação. Brazilian fournal of Development, 6(3):12625-12635, 2020.

[2] Laís de Paiva Freire, João Victor Queiroz, Jarbele Cássia da Silva Coutinho, and Verônica Maria Lima Silva. Encontros de tutoria de programação introdutória através de metodologias ativas: um estudo piloto. In Proceedings of the I Encontro do Oeste Potiguar - Versão Pocket, IECOPPOCKET '20, pages 1-8. ECOP, 2020.

[3] João Victor Queiroz, Larissa Milena Rodrigues, and Jarbele.C Coutinho. Um relato dos fatores motivacionais na aprendizagem de programação na perspectiva de alunos iniciantes em programação da universidade federal rural do semi-Àrido campus pau dos ferros-rn. In Proceedings of the III Encontro do Oeste Potiguar, ECOP '18, pages 90-96. ECOP, 2018.

[4] Gabriel Luídy Moreira, Wallace Holanda1, Jarbele Cássia da S. Coutinho, and Ferdinandy S. Chagas. Desafios na aprendizagem de programação introdutória em cursos de ti da ufersa, campus pau dos ferros: um estudo exploratório. In Proceedings of the III Encontro do Oeste Potiguar, ECOP '18, pages 90-96. ECOP, 2018 .

[5] Wallace Holanda, Jarbele Coutinho, and Laysa Fontes. Uma intervenção metodológica para auxiliar a aprendizagem de programação introdutória: um estudo experimental. Anais dos Workshops do Congresso Brasileiro de Informática na Educação, 7(1):699, 2018.

[6] N Hawi. Causal attributions of success and failure made by undergraduate students in an introductory-level computer programming course. Computers \& Education, 54(4):1127-1136, May 2010. 
[7] P. S. C. Santos, L. G. J. Araujo, and R. A. Bittencourt. A mapping study of computational thinking and programming in brazilian k-12 education. In 2018 IEEE Frontiers in Education Conference (FIE), pages 1-8, Oct 2018.
[8] J.J. Garrett. The Elements of User Experience: User-Centered Design for the Web and Beyond. Voices That Matter. Pearson Education, 2010. 